\title{
Diastolic dysfunction for nephrologists: diagnosis at the point of care
}

\author{
iD Marcus G Bastos ${ }^{\mathbf{1}, 2,3}$ \\ (iD) Ana Luisa Vieira ${ }^{4}$ \\ (iD) José M Pazeli j ${ }^{4}$ \\ (D) Arise GS Gali1
}

\begin{abstract}
1. Faculdade de Medicina da Universidade Federal de Juiz de Fora, MG, Brasil. 2. UNIFAGOC, Ubá, MG, Brasil. 3. Faculdade de Ciências Médicas e da Saúde (SUPREMA), Juiz de Fora, MG, Brasil. 4. Serviço de nefrologia, Santa Casa de Misericórdia de Barbacena, Faculdade de Medicina de Barbacena, Barbacena, MG, Brasil.
\end{abstract}

\section{SUMMARY}

Cardiovascular diseases are important causes of morbidity and mortality in the course of chronic kidney disease (CKD). Diastolic dysfunction (DD) may progress with the clinical manifestation of heart failure, known as heart failure with preserved ejection fraction, a condition that precedes systolic dysfunction. The early identification of DD by echocardiography at the point-of-care before the appearance of symptoms and signs of pulmonary congestion and the implementation of appropriate treatment can improve the prognosis of CKD. This review article briefly addresses DD in kidney disease and presents a practical approach to the echocardiographic diagnosis of DD at the point of care.

KEYWORDS: Heart Failure, Diastolic. Echocardiography. Heart failure. Renal Insufficiency, Chronic.

\section{INTRODUCTION}

Patients with chronic kidney disease (CKD) associated with cardiovascular disease (CVD) have a higher risk of death than the general population'. About $40 \%$ of patients with stage 4-5 CKD have a diagnosis of heart failure, as seen in the USRDS Annual Data Report of $2015^{2}$. Consequently, in patients with CKD, heart failure $(\mathrm{HF})$ must be diagnosed and treated early. HF with preserved ejection fraction (HFpEF) describes HF due to diastolic dysfunction (DD) occurring with normal or slightly reduced ejection fraction, and without the attributable valvular disease ${ }^{3}$. $\mathrm{HFpEF}$ is still underdiagnosed and has been implicated as a significant contributor, if not the leading cause, of congestive HF in such patients ${ }^{4}$. The importance of identifying $\mathrm{HFpEF}$ is its association with poor prognoses. For example, when 4,550 patients in the general population were followed-up for five years, 2,126 with HFpEF and 2,424 with heart failure with reduced ejection fraction [HFrEF], the survival rate was almost the same regardless of whether the ejection fraction was reduced or not (risk-standardized for death, 0.96; $\mathrm{p}=$ $0.03)^{5}$. In this short review, we discuss DD succinctly and present a practical approach to identifying it at the point of care, essential when the comprehensive 
echocardiography cannot be obtained or is not immediately available to the nephrologist.

\section{Heart failure with preserved ejection fraction} in kidney disease

HFpEF is a disease that affects the elderly and patients who have, on average, at least four comorbid conditions. The prevalence of CKD is high (and rising) in part due to the aging population who frequently present multiple comorbidities ${ }^{6}$. It is not surprising that HFpEF is frequently diagnosed in these patients ${ }^{7}$. The occurrence of DD in CKD can be identified in patients in conservative and dialytic treatments, as well as in transplant recipients and critically ill renal patients. In patients with CKD not yet on dialysis and complaining of dyspnea, HFpEF was diagnosed in $73 \%$, and in $44,6 \%$, the HFpEF was the only explanation for the dyspnea ${ }^{8}$. Also, in patients on dialysis subjected to transthoracic echocardiography (TTE), left ventricular hypertrophy was found to be the primary anatomical abnormality and DD, present in $81 \%$ of cases, the main functional alteration ${ }^{9}$. Notably, DD preceded systolic dysfunction, which makes this study's findings even more interesting for nephrologists.

In renal transplant, DD is also a frequent and dangerous complication, since the vast majority of these patients present left ventricular hypertrophy due to volume overload and hypertension during their dialysis treatment. Therefore, it is not surprising that transplant patients are also diagnosed with $\mathrm{HFpEF}^{\mathbf{1 0}}$.

Nephrologists looking after patients in the intensive care unit may also deal with clinical conditions associated with left ventricular DD, which is associated with mortality in critically ill patients ${ }^{11}$. Thus, for example, in critically ill patients who need fluid resuscitation, if the assistant nephrologist can assess DD, the fluid replacement could be promptly implemented even before the availability of comprehensive echocardiography by cardiologists.

When present, the symptoms and signs of HFpEF are indistinguishable from those observed in HFrEF: neurohumoral activation with sodium and water retention (edema); paroxysmal nocturnal dyspnea; orthopnea; jugular vein distension; third heart sound; hepatomegaly; and cardiomegaly on X-ray ${ }^{12}$. Due to the limitations of myocardial relaxation and compliance during diastole, the left ventricular end-diastolic pressure (LVEDP) in patients with DD is already high previously to physical activity. Consequently, the cardiac output does not increase, which makes these patients highly intolerant to physical exercise. Similarly, these patients do not tolerate large volume fluctuations, making them more susceptible to intradialytic hypotension ${ }^{13}$.

\section{Pathophysiology of diastolic dysfunction}

Although a detailed description of DD's pathophysiology is beyond the scope of this review, a basic comprehension of the various grades of DD is essential for nephrologists to understand the echocardiographic findings that will allow them to diagnose DD at the point of care.

Hypertension is considered the leading risk fac- tor for the development of HFpEF. Other precipitating factors such as diabetes mellitus, obesity, and coronary artery disease, also common in patients with CKD, may explain the high prevalence of DD observed in kidney patients ${ }^{14}$. Potential explanations for this increased prevalence of DD include aortic stiffness and volume overload, which are frequently observed in CKD, particularly in the more advanced stages of the disease ${ }^{15}$.

The left ventricle could be compared to a powerful propulsion pump, in systole, and suction pump, in diastole. Diastole comprehends the period between the closure of the aortic valve (end of systole) and the closure of the mitral valve (end of diastole), and it comprises four distinct and consecutive phases: isovolumic relaxation, early rapid diastolic filling, diastasis, and atrial contraction ${ }^{16}$. The first two phases of diastole are active and require adenosine triphosphate (ATP) production from the myocardium. During isovolumetric relaxation, $\mathrm{LV}$ pressure decreases with the closure of the aortic valve but without a change in volume. When the pressure drops below the atrial pressure, the mitral valve opens. Then, the initial early rapid diastolic filling period occurs, with the blood being suctioned by the LV from the left atrium. Several parameters, including myocardial relaxation, LV compliance, and the atrioventricular pressure gradient, influence the velocity of blood flow through the mitral valve. As the amount of blood in the LV increases, gradual pressure equalization occurs with the left atrium, which characterizes diastase, a period in which transmitral blood flow is minimal. The final phase of diastole occurs with atrial contraction, which transiently increases left atrial pressure and promotes late LV filling. The phases of diastole in the right ventricle are similar to those described for $\mathrm{LV}$, except for the 
total duration, which is shortened due to a more extended systolic ejection period ${ }^{17}$.

HFpEF, when DD becomes clinically evident, results from different mechanisms, such as ventricular-arterial coupling, chronotropic incompetence, and endothelial dysfunction, but without a doubt, DD is the most significant ${ }^{18}$. DD results in increased LVEDP, increased pressure in the left atrium, and may lead to the development of symptoms and signs of pulmonary congestion.

\section{Assessment of diastolic dysfunction}

TTE is the most commonly used propaedeutic tool in the diagnosis of DD. The American Society of Echocardiography (ASE) has published guidelines for the assessment of diastolic dysfunction ${ }^{17}$. The parameters suggested for the diagnosis of DD include: 1. transmitral blood inflow by pulsed-wave Doppler (PWD); (2) mitral annulus downward velocity (septal and lateral walls) using tissue Doppler imaging (TDI); (3) left-atrial volume index; and (4) peak tricuspid regurgitation velocity. DD is present if more than half of the available parameters meet the cutoff values. However, all these measurements are challenging to obtain, time-consuming, and impractical at the point of care. Besides, the ASE guidelines do not categorize DD of a third of septic patients and rate $41 \%$ of patients with elevated $\mathrm{E} / \mathrm{e}^{\prime}$ as normal ${ }^{19}$.

Point-of-Care evaluations of DD in everyday nephrology, whether in office, ward, or intensive care unit are used mainly to answer two fundamental questions: (1) is DD present?; and (2) is the LVEDP high?

In this context, DD can be assessed qualitatively and quantitatively. Qualitatively, DD can be inferred by comparing the linear size of the left atrium (LA) with the size of the aorta and the right ventricle outflow tract in an image obtained in the cardiac parasternal long-axis view at the end of diastole. The size of LA does not change acutely, and in the absence of significant mitral regurgitation or stenosis, its enlargement represents chronically elevated LVEDP ${ }^{20}$. Under normal conditions, the size of the left atrium is similar to that of the aorta and right ventricle outflow tract, and this evaluation is known as the rule of thirds (Figure 1). A left atrium-to-aorta diastolic diameter ratio $>1$ correlates with LA enlargement and may be useful as a quick bedside technique that suggests $D^{21}$. Besides, the assessment of the left atrium has prognostic importance. For instance, a left atrial volume index (LAVi) lower than $32 \mathrm{~mL} / \mathrm{m}^{2}$, adopted as a normal superior limit, was associated with a higher survival rate compared to values $>32 \mathrm{~mL} / \mathrm{m}^{2}$ and was shown to be an independent predictive value of prognosis in patients subjected to hemodialysis?.

Moreover, DD can be assessed qualitatively by the visual analysis of the amplitude of the basal displacement of the septal annulus of the mitral valve during diastole. In conditions of normality, this displacement is large, while in DD, it is limited in amplitude ${ }^{17}$.

Quantitatively, DD can be analyzed through PWD and TDI ${ }^{19}$. For instance, in septic patients subjected to TTE, a simplified definition of DD, based on transmitral

FIGURE 1. RULE OF THIRDS: PARAESTERNAL LONG-AXIS VIEW SHOWING THE RELATIONSHIP BETWEEN THE LEFT ATRIUM, AORTIC ROOT, AND RIGHT VENTRICLE OUTFLOW TRACT DIAMETERS IN DIASTOLE IN A HEALTH SUBJECT (A) AND IN A PATIENT WITH AN INCREASED LEFT ATRIUM (ASTERISK) WITH DIATOLIC DYSFUNCTION (B)
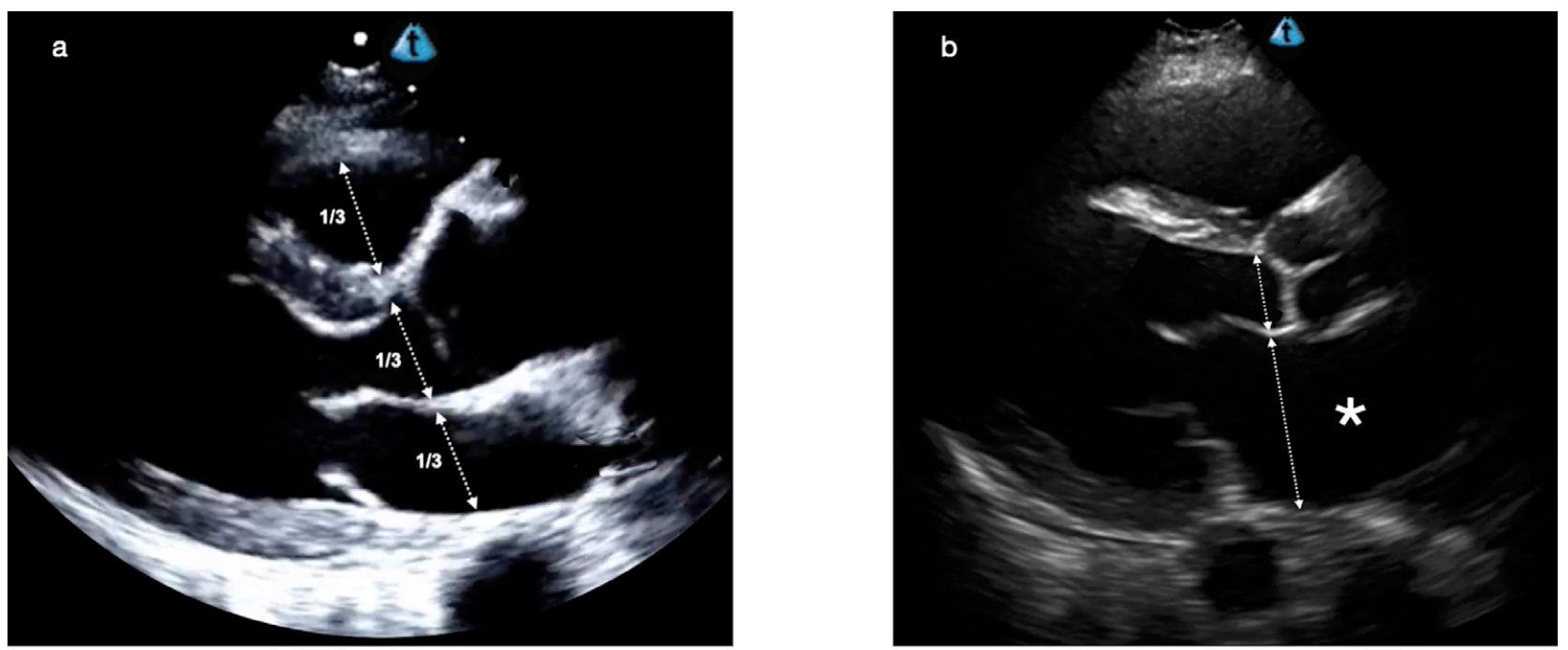

Marcus Gomes Bastos 
FIGURE 2. DEGREES OF DIASTOLIC DYSFUNCTION BASED ON TRANSMITRAL AND TISSUE DOPPLER IMAGING SHOWING BLOOD FLOW VELOCITIES THROUGH THE MITRAL VALVE (E AND A WAVES) AND THE VELOCITY OF THE BASAL DISPLACEMENT OF THE MITRAL VALVE ANNULUS TOWARDS THE BASE OF THE HEART (E' AND A' WAVES); NORMAL AND DIFFERENT STAGES OF DIASTOLIC DYSFUNCTION.

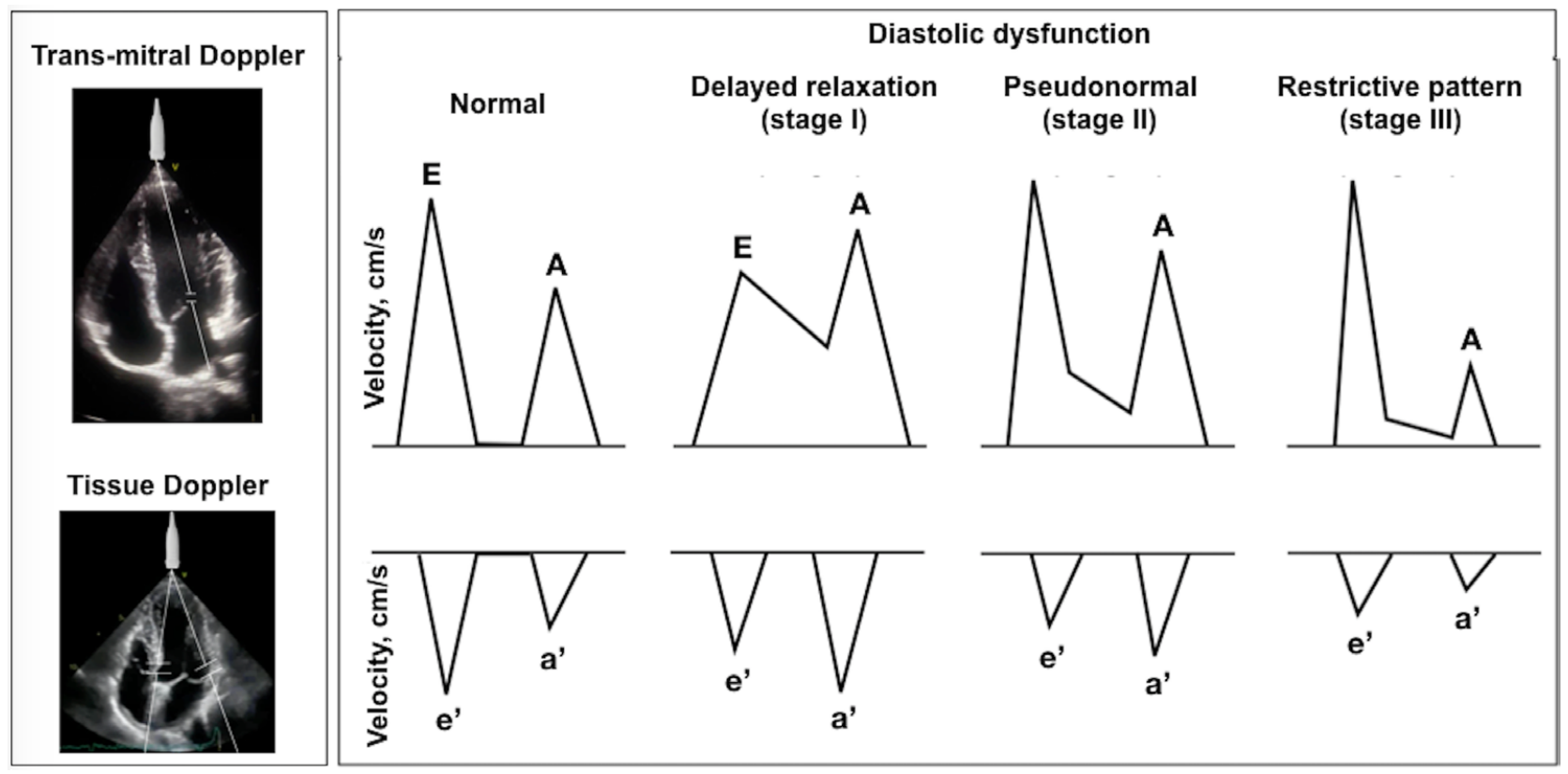

Marcus Gomes Bastos

blood inflow and mitral annulus downward velocity, categorized more patients than the American Society of Echocardiography 2016 definition (78\% vs. 71\%, $p=0.035$ ) and showed reasonable correlation with comorbidities (hypertension, diabetes, and myocardial infarction) $)^{19}$.

The assessment of transmitral blood flow velocity by PWD is performed with phased-array transducer (1-5 MHz), placing the sample gate on the free-edge of mitral valve leaflets in the apical 4-chamber view of the heart. The blood flow velocity from the left atrium into the LV during the early rapid diastolic filling is measured. Since the direction of the blood flow is towards the ultrasound probe positioned at the tip of the heart, the signal obtained is an upward deflection, denominated $\mathrm{E}$ wave. The final phase of diastole, which results from atrial contraction, also presents an upward deflection and is represented by the $\mathrm{A}$ wave.

The PWD patterns allow categorizing the DD (Figure 2). In normal diastole, the majority of diastolic filling occurs during the early phase of the cardiac cycle (passive pull of $\mathrm{LV}$ relaxation), graphically represented by an $\mathrm{E}$ wave higher than the $\mathrm{A}$ wave $(\mathrm{E} / \mathrm{A}>0.8)$. In grade I DD, the impairment in myocardial relaxation results in a reduced rate of decrease of $\mathrm{LV}$ pressure. As a consequence, there is a decrease of the normal "pull" during early LV diastole and a "push" of the remaining blood into the LV during the atrial contraction. Grade
I DD has a very distinct mitral inflow pattern with an $\mathrm{E} / \mathrm{A}$ ratio $<0.8$. This is the most frequent DD; however, because LVEDP is normal, symptoms of heart failure are not yet apparent. In grade II DD, there is a transition from abnormal relaxation to an impairment of both ventricular relaxation and compliance. The $\mathrm{E}$ wave is again higher than the A wave (resulting in the term pseudonormal), but now due to a concurrent increase in the left atrial pressure, which pushes the blood flow across the mitral valve $(\mathrm{E} / \mathrm{A}>0.8)$. Grade III DD represents a restrictive filling pattern, in which relaxation and compliance continue to worsen, leading to severe increased left atrial pressure and size, which masks underlying abnormalities. The $\mathrm{E}$ wave is also higher than the A wave (E/A rate $>2$ ). In grades II and III DD, the ventricular diastolic filling is compromised, the LVEDP increases, and the patient develops symptoms and signs of pulmonary congestion ${ }^{17,19}$.

TDI evaluates the slower speed of tissue, and it measures the velocity of the longitudinal displacement of the mitral valve annulus towards the base of the heart (Figure 2$)^{17}$. The sample gate is positioned at the intersection of the mitral annulus and the septum and/ or the LV lateral wall. As TDI assesses the velocity of myocardial tissue movement, the values measured are much lower than the transmitral blood flow velocity. Because the analysis of the mitral annular movement is towards the base of the heart, i.e., the movement of 
the tissue is in the opposite direction to the probe positioned at the tip of the heart (in the apical four-chamber view), the graphical representation of the wave is negative. In normal diastole, the movement of the mitral annulus during the early rapid diastolic filling is represented by the e' wave (normal velocity is $\geq 8$ $\mathrm{cm} / \mathrm{s}$ for septal e' and $\geq 10 \mathrm{~cm} / \mathrm{s}$ for lateral annulus e'), which is higher than the a' wave, a representation of the atrial contraction. Fortunately, only the e' wave is usually needed to assess DD, which explains its frequent use as a surrogate for the $\mathrm{LV}$ relaxation rate. The higher the e', the faster the ventricular relaxation and the better the diastolic filling. As the relaxation and myocardial compliance worsen, expressed as e' wave abnormally low in amplitude $(<8 \mathrm{~cm} / \mathrm{s}$ for septal e' and $<10 \mathrm{~cm} / \mathrm{s}$ for lateral annulus e'), the $\mathrm{LV}$ diastolic filling raises, and the atrial pressure consequently increases $^{17}$. As shown in Figure 2, in grade I DD, the e' wave is $<8 \mathrm{~cm} / \mathrm{s}$ (septal e') or $<10 \mathrm{~cm} / \mathrm{s}$ (lateral annulus e') and shorter than the a' wave. In grade II DD, the e' wave is also $<8 \mathrm{~cm} / \mathrm{s}$ for septal e' and $<10 \mathrm{~cm} / \mathrm{s}$ for lateral annulus e' and shorter than the a' wave, a finding that allows differentiating normal diastole from pseudonormal DD. Finally, in grade III DD, the e' wave is even smaller, and the a' wave sometimes almost does not exist ${ }^{17}$.

FIGURE 3. B-LINES ARE DEFINED AS DISCRETE LASERLIKE VERTICAL HYPERECHOIC REVERBERATION ARTIFACTS THAT ARISE FROM THE PLEURAL LINE, EXTEND TO THE BOTTOM OF THE SCREEN WITHOUT FADING, AND MOVE SYNCHRONOUSLY WITH LUNG SLIDING

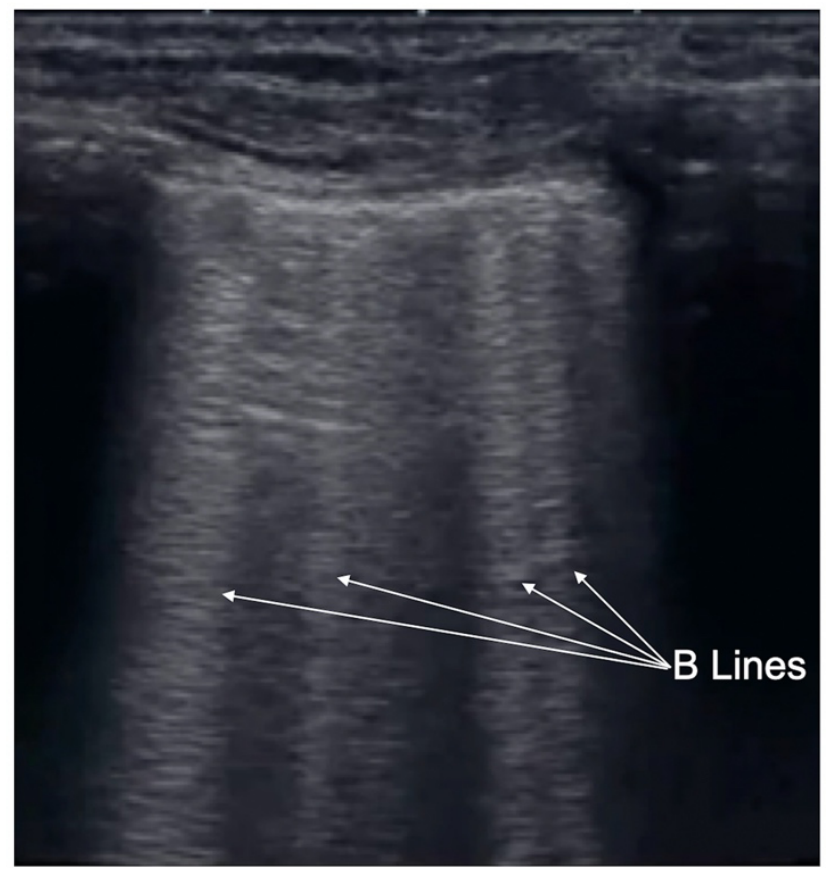

The importance of answering the second question, "Is the LVEDP high?" is because elevated left ventricular filling pressure correlates with increased pressure in the left atrium and pulmonary capillary wedge pressure, therefore, with symptoms and signs of $\mathrm{HFpEF}^{17,22}$.

LVEDP determination by echocardiography is easy and obtained by dividing the transmitral blood flow velocity by the velocity of the mitral valve towards the base of the heart (E/e' ratio). The LVEDP is normal when the E/e' ratio is $\leq 8$ and considered increased when it is $>15$. Values between 9 and 15 are considered indeterminate ${ }^{22}$. Additionally, the E/e' ratio can be used to estimate pulmonary capillary wedge pressure (PCWP) by this simple formula: PCWP $=1.9+$ $\left(1.24^{*} \mathrm{E} / \mathrm{e}^{\prime}\right)^{23}$.

In cases of indeterminate LVEDP, two other assessments can be used: 1 . visual evaluation of the left atrium size, which, if increased, suggests elevated LVEDP; and 2. assessment of B lines by lung ultrasound. $\mathrm{B}$ lines are lung artifacts seen as vertical lines that originate at the visceral pleura, move with the respiration, and erase the $\mathrm{A}$ lines (Figure 3$)^{24}$. In the right clinical context, three or more B lines, in two or more intercostal spaces in both lungs, should be considered a diagnostic for pulmonary edema, with $94 \%$ sensitivity and $92 \%$ specificity ${ }^{25,26}$. The assessment of B lines does not require sophisticated software or a prolonged learning curve and is performed at the bedside in just a few minutes with the same probe used for echocardiography. It has been shown that B lines exhibit a good correlation with lung congestion diagnosed by chest radiography and brain natriuretic peptide levels ${ }^{25}$ and correlates with non-invasively and invasively measured LVEDP ${ }^{27,28}$.

In CKD, particularly in patients undergoing pre-dialysis treatment, the usefulness of the E/e' ratio as a predictive factor for CVD and mortality has not been thoroughly studied but may be promising. For example, the echocardiographic assessment with PWD e TDI in patients of both genders, with a mean age of 61 years, and CKD stages 3 (25 patients), 4 (22 patients) and 5 (89 patients), followed-up for five years, showed that patients with E/e' ratio $>15$ had lower survival rates and higher cardiovascular events ${ }^{8}$.

However, it is important to recognize that there are cases where the point of care echocardiography cannot provide diagnostic certainties. For instance, in $\mathrm{AF}$, atrial contraction is lost. Consequently, there is no transmittal A wave, and hence the E/A ratio cannot 
be used. In this case, the use of the $\mathrm{E} / \mathrm{e}$ ' ratio, which is independent of atrial influence, correlates well with elevated LVEDP and can be used as a marker for DD in AF. Other conditions that may demand comprehensive echocardiography are abnormalities of basal left ventricular motion, mitral annular disease, and improper cardiac windows. However, if the echocardiologist's assessment also proves inconclusive, invasive evaluation of the left ventricular filling pressure remains the gold standard modality of choice ${ }^{27}$.

\section{CONCLUSION}

DD is a cardiovascular complication in CKD and is potentially associated with undesirable outcomes. Determining DD and the LVEDP through the E/e' ratio obtained by PWD and TDI is a non-invasive method that allows predicting mortality and cardiovascular events at the point of care. Although we realize that DD is a complex condition, the simplification of its assessment, as shown in this review, can attract nephrologists to incorporate it into their everyday practice. However, we recognize that further prospective studies are warranted to validate and extend this simplified definition of DD, particularly in nephrology.

\section{Conflicts of interest}

The authors declare there are no conflicts of interest that could have influenced the work presented herein.

\section{Author's Contribution}

Conceptualization, structuring of the manuscript, critical review, and final approval of this version: All authors; Drafting of the manuscript: Marcus G Bastos

\section{SUMÁRIO}

As doenças cardiovasculares são causa importante de morbidade e mortalidade no curso da doença renal crônica (DRC). A disfunção diastólica (DD) pode evoluir com insuficiência cardíaca manifesta clinicamente, denominada insuficiência cardíaca com fração de ejeção preservada, e precede a disfunção sistólica. A identificação precoce da DD pela ecocardiografia "point of care", antes do aparecimento dos sintomas e sinais de congestão pulmonar, e a implementação de tratamento adequado podem melhorar o prognóstico da DRC. Este artigo de revisão aborda brevemente a DD na doença renal e apresenta uma abordagem prática para o diagnóstico ecocardiográfico da DD à beira do leito

PALAVRAS-CHAVES: Insuficiência Cardíaca Diastólica. Ecocardiografia. Insuficiência cardíaca. Insuficiência renal crônica.

\section{REFERENCES}

1. Wright J, Hutchison A. Cardiovascular disease in patients with chronic kidney disease. Vasc Health Risk Manag. 2009;5:713-22.

2. United States Renal Data System. 2017 USRDS annual data report: executive summary. 2017;71(3 Suppl 1):S1-8. [cited 2020 Aug 2]. Available from: https://www.usrds.org/media/2285/2017_volume_1_ckd_in_the_us.pdf

3. Owan TE, Hodge DO, Herges RM, Jacobsen SI, Roger VL, Redfield MM. Trends in prevalence and outcome of heart failure with preserved ejection fraction. N Engl J Med. 2006;355(3):251-9.

4. Bonow RO, Udelson JE. Left ventricular diastolic dysfunction as a cause of congestive heart failure. Mechanisms and management. Ann Intern Med. 1992;117(6):502-10.

5. Owan TE, Hodge DO, Herges RM, Jacobsen SJ, Roger VL. Trends in prevalence and outcome of heart failure with preserved ejection fraction. New Engl | Med. 2006;355(3):251-9.

6. Gansevoort RT, Correa-Rotter R, Hemmelgarn BR, Jafar TH, Heerspink HJ, Mann JF, et al. Chronic kidney disease and cardiovascular risk: epidemiology, mechanisms, and prevention. Lancet. 2013;382(9889):339-52.

7. Barberato $\mathrm{SH}$, Pecoits Filho R. Prognostic value of left volume index in hemodialysis patients. Arq Bras Cardiol. 2007;88(6):643-50.

8. Kim MK, Kim B, Lee JY, Kim JS, Han BG, Choi SO, et al. Tissue Doppler-derived E/e'ratio as a parameter for assessing diastolic heart failure and as a predictor of mortality in patients with chronic kidney disease. Korean Intern Med. 2013;28(1):35-44.
9. Pecoits-Filho R, Bucharles S, Barberato SH. Diastolic heart failure in dialysis patients: mechanisms, diagnostic approach, and treatment. Semin Dial. 2012;25(1):35-41.

10. Bang JY, Lee JB, Sang BH, Kim YH, Han DJ, Song JG, et al. High left ventricular filling pressure on doppler echocardiography is associated with graft failure and overall mortality following kidney transplantation. J Cardiothorac Vasc Anesth. 2016;30(3):585-91.

11. Sanfilippo F, Corredor C, Fletcher N, Landesberg G, Benedetto U, Foex P, Cecconi M. Diastolic dysfunction and mortality in septic patients: a systematic review and meta-analysis. Intensive Care Med. 2015;41(6):1004-13.

12. Kapila R, Mahajan RP. Diastolic dysfunction. Continuing Education in Anaesthesia Critical Care \& Pain. 2009;9(1):29-33.

13. Tzatzaki E, Spartalis M, Kamperidis V, Spartalis E, Giannakoulas G, Karvounis $\mathrm{H}$. Diastolic dysfunction in end-stage renal disease patients. Hell J Atheroscler. 2017;8(2):96-102.

14. Teo LY, Chan LL, Lam CS. Heart failure with preserved ejection fraction in hypertension. Curr Opinion Cardiol. 2016;31(4):410-6.

15. London GM. Cardiovascular disease in chronic renal failure: pathophysiologic aspects. Semin Dial. 2003;16(2):85-94.

16. Patel PA, Ali N. Heart failure with preserved ejection fraction (HF-PEF): a mini-review. Ann Cardiol Vasc Med. 2017;1:1003.

17. Nagueh SF, Smiseth $O A$, Appleton CP, Byrd BF $3^{\text {rd }}$, Dokainish H, Edvardsen $T$, et al. Recommendations for the evaluation of left ventricular diastolic 
function by echocardiography: an update from the American Society of Echocardiography and the European Association of Cardiovascular Imaging. Am Soc Echocardiogr. 2016;29(4):277-314

18. Sharma K, Kass DA. Heart failure with preserved ejection fraction: mechanisms, clinical features, and therapies. Circ Res 2014;115:79-96.

19. Lanspa MI, Olsen TD, Wilson EL, et al. A simplified definition of diastolic function in sepsis, compared against standard definitions. J Intensive Care 2019;7:14.

20. Melenovsky V, Borlaug BA, Rosen B, et al. Cardiovascular features of heart failure with preserved ejection fraction versus non failing hypertensive left ventricular hypertrophy in the urban Baltimore community: the role of atrial remodeling/dysfunction. J Am Coll Cardiol 2007;49:198-207.

21. Kimura BJ, Kedar E, Weiss DE, et al. A bedside ultrasound sign of cardiac disease: the left atrium-to-aorta diastolic diameter ratio. Am J Emerg Med 2010;28:203-7.

22. Ommen $\mathrm{SR}$, Nishimura RA, Appleton $\mathrm{CP}$, et al. Clinical utility of Doppler echocardiography and tissue Doppler imaging in the estimation of left ventricular filling pressures: a comparative simultaneous Doppler-catheterization study. Circulation 2000;102:1788-94.

23. Nagueh SF, Middleton KJ, Kopplen HA, Zoghbi WA, Quiñones MA. V.
Doppler Tissue Imaging: A Noninvasive Technique for Evaluation of Left Ventricular Relaxation and Estimation of Filling Pressures. JACC 1977;30:1527-33.

24. Volpicelli G, Elbarbary M, Blaivas M, et al. International Liaison Committee on Lung Ultrasound (ILC-LUS) for International Consensus Conference on Lung Ultrasound (ICC-LUS) (2012) International evidence-based recommendations for point-of-care lung ultrasound. Intensive Care Med 38:577-91.

25. Al Deeb M, Barbic S, Featherstone R, Dankoff।, Barbic D. Point-of-care ultrasonography for the diagnosis of acute cardiogenic pulmonary edema in patients presenting with acute dyspnea: a systematic review and meta-analysis. Acad Emerg Med 2014;21:843-52.

26. Jambrik Z, Monti S, Coppola V, Agricola E, Mottola G, Miniati M, Picano E, Usefulness of ultrasound lung comets as a nonradiologic sign of extravascular lung water. Am J Cardiol 2004;93:1265-70.

27. Borlaug BA, Kass DA. Invasive Hemodynamic Assessment in Heart Failure. Heart Fail Clin 2009;5:217-28.

28. Hubert A, Girerd N, Le Breton H, et al. Diagnostic accuracy of lung ultrasound for identification of elevated left ventricular filling pressure. Int I Cardiol 2019;28:62-8. 